\title{
Typology of the Ket finite verb
}

\author{
Edward Vajda \\ Western Washington University
}

\section{Introduction}

Finite verbs in Yeniseian are known for their formal elaboration, which strikes an obvious contrast with the comparatively straightforward suffixal agglutinating morphologies of other Inner Asian languages. The best-described Yeniseian language is Ket, the family's sole surviving member, spoken in three closely related dialects by a few dozen elderly people in central Siberia near the Yenisei River in the Turukhansk District of Russia's Krasnoyarsk Krai. New publications on the Ket finite verb over the past two decades make it possible to describe this unusual morphological object succinctly yet with precision, and even offer diachronic explanations for its most unusual features. The article consists of two main sections and a conclusion. The first section describes the verb's formal architecture, explaining what information must be included in the lexical entry of a Ket finite verb. The second explains how inflectional and lexical semantic categories are expressed, and offers a diachronic perspective on how Yeniseian verb structure developed. The conclusion summarizes how form and function in the Modern Ket verb are often mismatched, a situation arising in large part from the areal position of Yeniseian as an isolated microfamily surrounded by languages of a radically different morphological type. Along the way, credit is given to scholars whose research has shed important light on Ket verb structure. The present author also points out his own earlier missteps in analyzing this challenging morphological system. The article is dedicated to the outstanding typologist Bernard Comrie. As director of the Department of Linguistics at the Max Planck Institute for Evolutionary Anthropology (Leipzig, Germany) from 1998 to 2015, he invited Siberianists from across the globe to work collaboratively, greatly advancing the synchronic description of minority Eurasian languages as well as illuminating their genealogical and areal relationships. 


\section{The formal architecture of Ket verb morphology}

The most striking feature of the Ket finite verb is its rigid position class structure, which involves a complex interdigitation of lexical and grammatical morphemes quite unlike the neighboring suffixal agglutinating languages. The authors of the first two fundamental descriptions of the Ket verb (Dul'zon 1968; Krejnovich 1968) essentially treated every stem as irregular, which was fortuitous since their descriptions were much richer in conjugated example forms than might otherwise have been the case. In actual fact, many regular patterns underlie the formal surface diversity, including three core principles of structure. The first is that virtually every conjugated form adheres to one and the same position-class template, though historical investigation shows that metathesis has altered this linear arrangement in significant ways. Second, the template's lexical morphemes are discontinuous, being separated by grammatical affixes in most forms. Third, the Ket verb stem is a position-class formula that specifies not only the lexical morphemes but also the locations of subject and object agreement markers and the choice of tense-mood morpheme shapes - neither feature being predictable by any overarching grammatical principle.

Let us begin with the position-class template that underlies every Ket verb stem and regulates its conjugated forms:

\begin{tabular}{|c|c|c|c|c|c|c|c|c|c|}
\hline P8 & P7 & P6 & P5 & P4 & P3 & P2 & P1 & P0 & P-1 \\
\hline $\begin{array}{c}\text { sbj } \\
\text { person } \\
\text { agr } \\
\text { or } \\
\text { detrans } \\
\text { marker }\end{array}$ & $\begin{array}{c}\text { incor- } \\
\text { porated } \\
\text { noun, } \\
\text { modifier, } \\
\text { or action } \\
\text { nominal }\end{array}$ & $\begin{array}{l}\text { obj } \\
\text { or } \\
\text { sbj } \\
\text { agr }\end{array}$ & $\begin{array}{c}\text { thematic } \\
\text { consonant(s) } \\
(k, t, d, q, h, \\
n, \eta, k d, k t, \\
n t, \eta t)\end{array}$ & $\begin{array}{c}3 \\
\text { anim } \\
\text { agr } \\
\text { or } \\
\text { conj } \\
(s / i \sim \\
\text { alo })\end{array}$ & $\begin{array}{c}3 \text { inan } \\
\text { agr } b \\
\text { or } \\
\text { thematic } \\
b\end{array}$ & $\begin{array}{l}\text { tense- } \\
\text { mood } \\
(n \sim l)\end{array}$ & $\begin{array}{c}1,2 \\
\text { sbj } \\
\text { or } \\
\text { obj } \\
\text { agr } \\
\text { or } \\
\text { result } \\
\text { affix }\end{array}$ & $\begin{array}{l}\text { BASE } \\
\text { (verb } \\
\text { root or } \\
\text { lexical } \\
\text { aspect } \\
\text { marker) }\end{array}$ & $\begin{array}{c}\text { anim } \\
\mathrm{pl} \\
\mathrm{sbj} \\
\text { agr }\end{array}$ \\
\hline
\end{tabular}

Table 1.

Ket finite verb template $(\mathrm{sbj}=$ subject, obj $=$ object, agr $=$ agreement, anim $=$ animate-class, inan $=$ inanimate class, detrans $=$ detransitive, $\mathrm{pl}=$ plural, result $=$ resultative, conj $=$ conjugation)

The position-class approach to Ket verb morphology was pioneered independently by Butorin (1995), Reshetnikov and Starostin (1995), and Werner (1997), while Vajda (2001) developed the template model shown above. The examples in (1) contain diverse morphological combinations, but each verb form can easily be divided according to the ten position-classes listed in Table 1: 
(1) Ket verbs with diverse position class combinations

a. $\quad d^{8}-a l a^{7}-b o^{6}-k^{5}-s^{4}-a q^{0}-i n^{-1}$ $3 \mathrm{SBJ}^{8}$-out ${ }^{7}$-1SG.OBJ ${ }^{6}$-with ${ }^{5}$-PRES ${ }^{4}$-go ${ }^{0}$-ANIM.PL.SBJ ${ }^{-1}$

'They lead me out.'

b. $\quad k^{8}-e d a^{7}-q^{5}-o^{4}-l^{2}-d i^{1}-d a^{0}$

$2 \mathrm{SBJ}^{8}$-send ${ }^{7}$-INCEPT ${ }^{5}$-PAST ${ }^{4 / 2}$-1 SG.OBJ ${ }^{1}$-ITER.TRANS ${ }^{0}$

'You (SG) used to send me.'

c. $\quad t i p^{7}-d i^{1}-b e d^{0}$

$\operatorname{dog}^{7}-1$ SG.SBJ ${ }^{1}$-have ${ }^{0}$

'I have a dog.'

d. $\quad b a^{6}-k^{5}-i n^{2}-s a a l^{0}$

1SG.SBJ ${ }^{1}-\mathrm{TC}^{5}$-PAST ${ }^{2}$-spend.night ${ }^{0}$

'I spent the night.'

Several position classes display surprising alternations in function. The semantic contrasts between subject vs. object (in positions 6, 4, 3 and 1), verb root vs. modifier (position 7), and verb root vs. aspect or transitivity marker (base position) are in fact strictly constrained and also afford pathways toward understanding the verb's historical development. In other words, there is astonishingly order submerged within the apparent chaos.

The second core principle of Ket finite verb structure is that the basic meaning of the stem is expressed by lexical morphemes in the non-adjacent positions P7, P5, and P0. Verb stems can be categorized according to which of these three positions are actually filled. Position P0 is called the 'base' because it represents the original locus of the verb root in the template. The oldest and structurally most basic stems lack morphemes in P7 and P5, so that their conjugated forms contain only the base and grammatical affixes:

(2) Simple, root-final Ket verb stems (lacking P7 and P5)

a. $\quad k^{8}-i l^{2}-a q^{0}-i n^{-1}$

$2 \mathrm{SBJ}^{8}$-PAST ${ }^{2}-\mathrm{go}^{0}$-ANIM.PL.SBJ ${ }^{-1}$

'You (PL) went (and returned).'

b. $\quad d u^{8}-n^{2}-\boldsymbol{q} \boldsymbol{o}^{0}$

3 MASC.SBJ ${ }^{8}-\mathrm{PAST}^{2}-\mathbf{d i e}^{\mathbf{0}}$

'He died.' 
c. $\quad d u^{8}-d i^{2}-t e d^{0}$

$3 \mathrm{MASC} \mathrm{SBJ}^{8}-1 \mathrm{SG} . \mathrm{OBJ}^{1}$-beat $^{\mathbf{0}}$

'He beats me.'

d. $\quad d a^{8}=b^{3}-i l^{2}-a^{0}$

3FEM.SG.SBJ ${ }^{8}=3 \mathrm{INAN} \mathrm{OBJ}^{3}-\mathrm{PAST}^{2}-\mathbf{e a t}^{\mathbf{0}}$

'She ate it.'

e. $\quad d u^{8}-b^{3}-i n^{2}-\boldsymbol{b o \boldsymbol { o }} \boldsymbol{k}^{0}-n^{-1}$

$3 \mathrm{SBJ}^{8}$-3INAN.OBJ ${ }^{3}$-PAST ${ }^{2}$-stretch ${ }^{\mathbf{0}}$-ANIM.PL.SBJ ${ }^{-1}$

'They stretched it.'

Although every stem fills the base position, on rare occasions the base morpheme itself elides phonologically in certain forms, as in the Southern Ket pronunciation of (2c) dabi' 'l 'she ate it' (cf. Central Ket dabi'la 'she ate it'). Verbs that contain a base but no P7 or P5 are strongly prefixing, their only suffix being the animate-class subject agreement marker in position P-1. Why a clitic boundary (=) separates the P8 subject marker from the rest of the morphological verb in forms like (2d) but not in others is explained in section 2.2 and can be ignored for now.

Many verb stems also contain a thematic consonant in position P5. These morphemes are usually difficult to etymologize, but in a small number of basic verbs they add a definable meaning to the verb stem.

(3) Root-final Ket verbs with P5 thematic consonant

a. $d^{8}=n^{5}-a^{4}-b^{3}-d o^{0}$

$3 \mathrm{SBJ}^{8}=$ round $^{5}-\mathrm{PRES}^{4}-3 \mathrm{INAN} . \mathrm{OBJ}^{3}-$-hop $^{0}$

'He fashions it by hewing (a round shape).'

b. $\quad d^{8}=\boldsymbol{d}^{5}-a^{4}-b^{3}-d o^{0}$

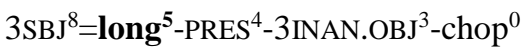

'He fashions it by hewing (a long object, such as a canoe).'

c. $\quad d^{8}=t^{5}-a^{4}-b^{3}-d o^{0}$

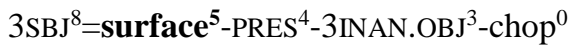

'He cuts it (rough-hews an object's surface).'

d. $\quad d^{8}=\boldsymbol{k}^{5}-a^{4}-b^{3}-d o^{0}$

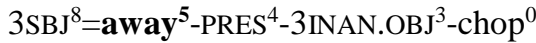

'He clears it (creates a trail by cutting away underbrush).' 
Unlike these examples with the base - $d o$ 'cut', the P5 affix in most stems is semantically opaque and must be glossed TC for 'thematic consonant'. A few stems contain more than one thematic consonant, showing that the P5 slot contains three linearly distinct classes of morphemes. These include, in order from left to right: 1) postpositions such as $k$ 'with' that require a preceding object marker; 2) spatial prefixes like $d$ 'long, along', $h$ 'flat surface, area', or $n$ 'round, around'; and 3) the pluractional marker $t$. Example (4a) contains a single thematic consonant, while (4b) contains two.

(4) Rare example of stem with concatenated P5 thematic consonants

a. $\quad d^{8}=t^{5}-a j^{4}-k a^{0}$

3 SBJ $^{8}=$ PLURACTIONAL $^{5}$-PRES $^{4}$-travel ${ }^{0}$

'He walks around (in various directions).'

b. $\quad d^{8}=b o^{6}-\boldsymbol{k} / \boldsymbol{t}^{5}-a j^{4}-k a^{0}$

$3 \mathrm{SBJ}^{8}=1 \mathrm{SG} . \mathrm{OBJ}^{6}$-with/PLURACTIONAL ${ }^{5}$-PRES ${ }^{4}$-travel ${ }^{0}$

'He leads me around (in various directions).'

Because concatentations of thematic consonants are completely unproductive, they occupy a single position class (P5) in the modern template.

Let us now turn to the last of the three core lexical position classes, the P7 incorporate slot. This position is usually unfilled in basic vocabulary. However, all productive stem patterns fill both $\mathrm{P} 7$ and $\mathrm{P}$, and most contain a P5 thematic consonant, as well. Stems with P7 can be called 'compound stems'. In compound stems with a semantically salient base, the $\mathrm{P} 7$ slot incorporates a noun (5a), adjective (5b), directional (5c), or adverb (5d) modifying the P0 base verb root.

(5) Ket incorporation in compound stems

a. $\quad d^{8}=s u u l^{7}-i l^{2}-b e d^{0}-n^{-1}$

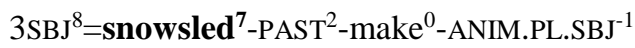

'They made a snowsled.'

b. $\quad d^{8}-\boldsymbol{u g d e} \boldsymbol{e}^{7}-t^{5}-a^{4}-b^{3}-\sin ^{0}$

$3 \mathrm{SBJ}^{8}$-long ${ }^{7}-\mathrm{TC}^{5}$-PRES ${ }^{4}$-3INAN.OBJ ${ }^{3}$-change $\mathrm{C}^{0}$

'He elongates it.'

c. $\quad d^{8}-\boldsymbol{a} \boldsymbol{k} \boldsymbol{a}^{7}-u^{6}-k^{5}-s^{4}-a q^{0}-i n^{-1}$

$3 \mathrm{SBJ}^{8}$-river.to.forest ${ }^{7}-3 \mathrm{INAN} . \mathrm{OBJ}^{6}$ - with $^{5}$-PRES ${ }^{4}$-go ${ }^{0}$-ANIM.PL.SBJ ${ }^{-1}$

'They carry it from the river up into the forest.' 
d. $\quad h e l^{7}-t^{5}-a^{4}-b^{3}-q u t^{0}$

out.of.place ${ }^{7}-\mathrm{TC}^{5}$-PRES ${ }^{4}$-3INAN.SBJ ${ }^{3}$-assume.position ${ }^{0}$

'It slips out of place.' 'It gets dislocated.'

In a majority of the three dozen or so productive Ket verb stem patterns, however, P7 contain what is called an 'action nominal' rather than a true incorporate. The P0 base in such stems has eroded semantically, and the action nominal expresses the stem's basic lexical meaning. The examples in (6) contain the action nominal bakdey 'pull':

(6) Ket action nominal-based verb stems (suffixing use of the template)

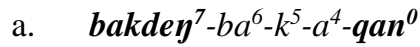

pull $^{7}$-1SG.SBJ ${ }^{6}$-TC ${ }^{5}$-PRES ${ }^{4}$-MOM.INCEPT ${ }^{0}$

'I start pulling (once).'

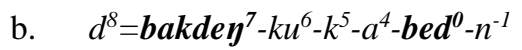

$1 \mathrm{SBJ}^{8}=$ pull $^{7}$-2SG.OBJ ${ }^{6}$-TC ${ }^{5}$-PRES ${ }^{4}$-ITER.TRANS ${ }^{0}$-ANIM.PL.SBJ ${ }^{-1}$

'We keep (on) pulling you (SG).'

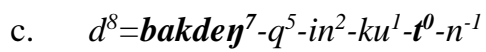

$1 \mathrm{SBJ}^{8}=$ pull $^{7}$-INCEPT ${ }^{5}$-PRES ${ }^{4}$-2SG.OBJ ${ }^{1}$-MOM.TRANS ${ }^{\mathbf{0}}$-ANIM.PL.SBJ ${ }^{-1}$

'We started pulling you (SG) once.'

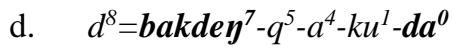

1 SBJ $^{8}=$ pull $^{7}$-INCEPT ${ }^{5}$-PRES ${ }^{4}-2$ SG.OBJ ${ }^{1}$-ITER.TRANS ${ }^{0}$

'We repeatedly (start to) pull you (SG).'

Used as a separate word outside the finite verb, an action nominal such as bakdey would express the following meanings, depending on context: 1) infinitival 'to pull', 2) gerundive '(the act of) pulling', and 3) participial '(someone who is) pulling' or '(someone or something that was or is being) pulled'. When incorporated into the P7 slot of a verb stem, the action nominal serves as the verb's semantic head. The P0 base in such stems has become grammaticalized as a suffix specifying transitivity (TRANS vs. INTRANS), start of action (INCEPT), or single complete action (MOM) in contrast to multiple or persistent action (ITER).

Krejnovich (1968) first recognized the difference between strongly prefixing stems with their semantic head in the original root position (the P0 base), and suffixing stems with a salient lexical morpheme near the verb's beginning (in the P7 incorporate position). Vajda (2009) argued that areal influence from the surrounding 
suffixing languages led to "pseudo-incorporation" of action nominals in P7 and semantic bleaching of the $\mathrm{P} 0$ base

a. Verb root in base position (P0) and original prefixing configuration of position classes:

\begin{tabular}{|c|c|c|c|c|c|c|c|c|c|}
\hline $\mathrm{P} 8$ & P7 & P6 & $\mathrm{P} 5$ & $\mathrm{P} 4$ & P3 & P2 & P1 & $\mathrm{P0}$ & P-1 \\
\hline $\begin{array}{l}\text { sbj } \\
\text { pers. } \\
\text { agr }\end{array}$ & $\begin{array}{l}\text { incor- } \\
\text { porated } \\
\text { noun or } \\
\text { modifier }\end{array}$ & $\begin{array}{l}\text { obj } \\
\text { or } \\
\text { sbj } \\
\text { agr }\end{array}$ & $\begin{array}{c}\text { thematic } \\
\text { consonan } \\
\mathrm{t}(\mathrm{s}) \\
(k, t, d, \\
\text { etc. })\end{array}$ & $\begin{array}{l}3 \text { anim } \\
\text { agr or } \\
\text { conj } \\
(s / i \sim \\
a / o)\end{array}$ & $\begin{array}{c}3 \text { inan } \\
\text { agr or } \\
\text { themat. } \\
b\end{array}$ & $\begin{array}{l}\text { tense- } \\
\text { mood } \\
(n \sim l)\end{array}$ & $\begin{array}{c}1,2 \mathrm{sbj} \\
\text { or obj } \\
\text { agr }\end{array}$ & $\begin{array}{l}\text { BASE } \\
\text { (verb } \\
\text { root) }\end{array}$ & $\begin{array}{c}\text { anim } \\
\text { pl } \\
\text { sbj } \\
\text { agr }\end{array}$ \\
\hline
\end{tabular}

b. Action nominal in P7 and innovative suffixing configuration:

\begin{tabular}{|c|c|c|c|c|c|c|c|c|c|}
\hline P8 & P7 & P6 & P5 & P4 & P3 & P2 & P1 & $\mathrm{P0}$ & P-1 \\
\hline $\begin{array}{c}\text { sbj } \\
\text { pers. } \\
\text { agr }\end{array}$ & $\begin{array}{c}\text { action } \\
\text { nominal } \\
\text { as } \\
\text { semantic } \\
\text { head }\end{array}$ & $\begin{array}{l}\text { obj } \\
\text { or } \\
\text { sbj } \\
\text { agr }\end{array}$ & $\begin{array}{c}\text { thematic } \\
\text { consonant } \\
\text { (s) } \\
(k, t, d, \\
\text { etc.) }\end{array}$ & $\begin{array}{l}3 \text { anim } \\
\text { agr or } \\
\text { conj } \\
(s / i \sim \\
\text { a/o })\end{array}$ & $\begin{array}{c}3 \text { inan } \\
\text { agr or } \\
\text { themat. } \\
b\end{array}$ & $\begin{array}{l}\text { tense- } \\
\text { mood } \\
(n \sim l)\end{array}$ & $\begin{array}{c}1,2 \\
\text { sbj or } \\
\text { obj } \\
\text { agr }\end{array}$ & $\begin{array}{c}\text { BASE } \\
\text { (aspect } \\
\text { or } \\
\text { transiti- } \\
\text { vity } \\
\text { suffix) }\end{array}$ & $\begin{array}{c}\text { anim } \\
\text { pl } \\
\text { sbj } \\
\text { agr }\end{array}$ \\
\hline
\end{tabular}

Table 2. Contrast between prefixing (a) and suffixing (b) verb models

The typological shift from prefixing to suffixing is also implicated in the partial change of P8 subject person agreement morphemes from prefix to special clitic. This is a convenient place to describe the phonological behavior of this position class, before concluding the discussion of lexical morpheme categories. Reshetnikov and Starostin (1995) were the first to identify the P8 subject markers as special clitics. Because they often elide, previous researchers were unaware of their structural presence in the morphological verb, making it impossible to give an accurate typological assessment of the Ket agreement system.

Vajda (2001) first identified the complex conditions under which P8 allomorphs are realized. They appear as syllabic prefixes only before certain short position-class strings:

\begin{tabular}{|c|c|c|}
\hline $\mathrm{P} 5-\mathrm{a}^{4}-\mathrm{P} 0$ & $\mathrm{P} 3-\left(\mathrm{n}^{2}\right)-\mathrm{P} 0$ & $\mathrm{P} 0$ \\
\hline$d i^{8}-k^{5}-a^{4}-d a q^{0}$ 'I live' & $d i^{8}-b^{3}-t e d^{0}$ 'I hit it' & $d \boldsymbol{i}^{8}$-doq 'I fly' \\
\hline $\boldsymbol{k} \boldsymbol{u}^{8}-\boldsymbol{k}^{5}-a^{4}-d a q^{0}$ 'you (SG) live' & $\boldsymbol{k} \boldsymbol{u}^{8}-b^{3}$-ted $d^{0}$ 'you (SG) hit it' & $\boldsymbol{k} \boldsymbol{u}^{8}-d o q^{0}$ 'you (SG) fly \\
\hline 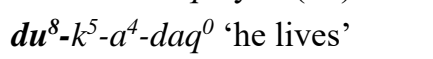 & $\boldsymbol{d} \boldsymbol{u}^{8}-b^{3}$-ted $d^{0}$ he hits it' & $\boldsymbol{d} \boldsymbol{u}^{8}$-doq $q^{0}$ 'he flies' \\
\hline $\boldsymbol{d} \boldsymbol{\partial}^{8}-k^{5}-a^{4}-d a q^{0}$ 'she lives' & $\boldsymbol{d} \boldsymbol{\partial}^{8}-b^{3}-t e d^{0}$ 'she hits it' & $\boldsymbol{d} \boldsymbol{d}^{8}-d o q^{0}$ 'she flies' \\
\hline
\end{tabular}

Table 3. Environments that preserve the full prefixal forms of P8 markers 
Before other position-class strings, feminine/inanimate $d \partial^{8}$ - changes its vocalism from [də] to [da]. Unlike $d \partial^{8}$-, which is always a prefix, $d a^{8}=$ is a clitic that can attach either to the verb or to a preceding word, as it normally does in fast speech, especially if the preceding word ends in a vowel. In examples with morpheme breakdown, the clitic boundary [=] after $d a^{8}$ indicates its ability to use either the verb or a preceding word as its host:

proclitic on verb enclitic on preceding word

$\boldsymbol{d \boldsymbol { a } ^ { 8 }}=o^{4}-l^{2}-d a q^{0}$ 'she lived' $b u=d a^{8} \quad o^{4}-l^{2}-d a q^{0}$ 'she lived' ( $b u$ 'she') $\boldsymbol{d} \boldsymbol{a}^{8}=b^{3}-i l^{2}-b e d^{0}$ 'she made it' $b u=\boldsymbol{d a} \boldsymbol{a}^{8} \quad b^{3}-i l^{2}-b e d^{0}$ 'she made it'

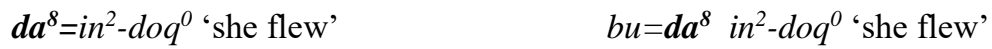

Table 4. Allomorphs of P8 feminine- and inanimate-class markers

The shape taken by the other three P8 markers in longer verb forms depends crucially on whether they precede a vowel or consonant. Before a vowel they assume the non-syllabic prefix forms $d$ - $\left(1^{\text {st }}\right.$ person, $3^{\text {rd }}$ person masculine-class singular or animate-class plural) and $k$ - ( $2^{\text {nd }}$ person $)$, which cannot encliticize to a preceding word. In this way they differ from feminine- or inanimate class $d a^{8}=$, which exhibits clitic behavior in longer strings even before a vowel (7b).

(7) Allomorphs of P8 markers in longer verbs strings before a following vowel

a. Prefix form only before a vowel-initial verb string

$$
\begin{array}{ll}
\text { quska } \boldsymbol{d}^{8}-o^{4}-l^{2}-d a q^{0} & \text { 'I lived in a tent.' } \\
\text { quska } \boldsymbol{k}^{8}-o^{4}-l^{2}-d a q^{0} & \text { 'You (SG) lived in a tent.' } \\
\text { quska } \boldsymbol{d}^{8}-o^{4}-l^{2}-d a q^{0} & \text { 'He lived in a tent.' }
\end{array}
$$

b. Prefix/clitic alternation in $3^{\text {rd }}$ person feminine/inanimate markers

quska $\boldsymbol{d} \boldsymbol{a}^{8}=o^{4}-l^{2}-d a q^{0}$ 'She lived in a tent.'

(quska \# da=oldaq quska=ra \# oldaq)

Before a consonant, the shortened allomorphs $d$ (1 $1^{\text {st }}$ person), $k$ ( $2^{\text {nd }}$ person), $d$ ( $3^{\text {rd }}$ person masculine-class singular or animate-class plural) normally elide unless they can encliticize to a preceding vowel-final word:

(8) Allomorphs of P8 markers in longer verbs strings before a consonant $d^{8}=n a n^{7}-s^{4}$-ibed ${ }^{0} \quad$ 'I make bread' (pronounced nansibed or $=d \#$ nansibed) $k^{8}=n a n^{7}-s^{4}-i b e d^{0} \quad$ 'you (SG) make bread' (nansibed or $=k \#$ nansibed)

$d^{8}=n a n^{7}-s^{4}$-ibed ${ }^{0} \quad$ 'he makes bread' (nansibed or $=d \#$ nansibed) $d a^{8}=n a n^{7}-s^{4}-i b e d^{0} \quad$ 'she makes bread' (da=nansibed or $=d a$ \# nansibed) 
The unusual allomorphy of P8 markers follows the Modern Ket preference for verbs with a lexical root in the first syllable, whether this root be an action nominal or a true incorporate. This tendency arose through influence from the surrounding suffixing languages and is not seen in the closely related Yugh language, where most P8 morphemes remained prefixes. In Ket, cliticization of P8 agreement markers fails to occur only in short strings like $d u^{8}-b^{3}-t e d^{0}$ 'he hits it', where the P8 syllable was retained to prevent the P0 base from occupying the verb's initial syllable, an ancient restriction apparently inherited from Proto-Yeniseian.

Returning to our discussion of stem elements, recall that the core lexical material is normally found in positions P7-P5-P0. The remaining seven position classes usually contain subject/object agreement or tense-mood affixes. However, three of the agreements slots occasionally contain lexical affixes that remain unchanged in all conjugated forms of the given stem. In slot P8 the inanimate-class agreement marker $d a={ }^{8}$ was occasionally reanalyzed as a detransitivizer on the basis of transimpersonal constructions such as 'it reddens me' $\rightarrow$ 'I blush' (Nefedov, Malchukov and Vajda 2011):

(9) Verb form with detransitivizing marker $d a=^{8}$

$$
\begin{aligned}
& \boldsymbol{d a}^{8}=\text { sulej }^{7}-b o^{6}-k^{5}-s^{4}-a^{0} \\
& \text { DETRANS }^{8}=\mathrm{red}^{7}-1 \mathrm{SG} . \mathrm{SBJ}^{6}-\mathrm{TC}^{5}-\mathrm{PRES}^{4} \text {-process.occurs }
\end{aligned}
$$

'I blush.'

Another lexical morpheme occurs in position P1, which normally expresses subject or object agreement. In some intransitives, $\mathrm{P} 1$ instead contains the resultative prefix $a-\sim j a \sim a j a$. This ancient element, which was part of the stem's lexical aspect system, once appeared in tandem with an intransitive or resultative suffix $-e j$ or $-\eta$, creating a sort of circumfix around the verb root. The suffix occupied a separate suffixal slot in Proto-Yeniseian, but in Modern Ket it interacts so irregularly with the verb root that Vajda $(2001,2004)$ treated it as part of the P0 base. The intransitive/resultative suffix remains discernable as a separate position class in Kott (Vajda, in press 2) and was also treated as a separate slot in Butorin's Ket template (Butorin 1995).

(10) Verb form with resultative $a^{1}$

$$
\begin{aligned}
& a^{4}-b^{3}-\boldsymbol{a}^{\boldsymbol{1}} \text {-bed } \\
& \text { PRES }^{4}-3 \text { INAN.SBJ } \\
&
\end{aligned}
$$


Finally, some stems have a lexical affix in $\mathrm{P} 3$, a position that normally contains the inanimate-class agreement marker $b^{3}$. Thematic $b^{3}$ resulted from metathesis of a consonant formerly occupying either P5 or P0. Some instances of lexical $b^{3}$ arose when the P5 area prefix $h$ (from earlier ${ }^{*} p$ ) co-occurred with another P5 thematic consonant and jumped forward across the P4 tense/mood marker into position P3. Because the metathesis also voiced ${ }^{*} p$ to $b$ (why this happened is not clear), it now resembles the homonymous inanimate-class agreement marker $b^{3}$, which occupies the same position much more frequently:

(11) Example of metathesis of P5 thematic *p into P3

a. $\quad d^{8}=q o q \partial^{7}-b a^{6}-h^{5}-a^{4}-t e d^{0}$

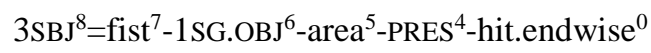

'He punches me (once).'

b. $\quad d^{8}=q o q \partial n^{7}-b a^{6}-t^{5}-a^{4}-\boldsymbol{b}^{3}-t e d^{0} \quad\left(<* d^{8}=q o q n^{7}-b a^{6}-p / t^{5}-a^{4}-t e d^{0}\right)$

$3 \mathrm{SBJ}^{8}=$ fists $^{7}-1 \mathrm{SG} . \mathrm{OBJ}^{6}$-PLURACTIONAL ${ }^{5}$-PRES $^{4}$-area ${ }^{3}$-hit.endwise ${ }^{0}$

'He punches me (repeatedly).'

The second type of thematic $b$ in position $\mathrm{P} 3$ resulted from a different metathesis. Where the initial $b$ of a P0 base derived historically from ${ }^{*} w$, it metathesized into position P3 in past-tense forms. In Modern Ket, this element must be regarded as lexical, though it has no independent function apart from the verb root, the phonological remainder of which still occupies position P0:

(12) Leftward metathesis of base anlaut $b<*_{w}$ into P3

a. $\quad d a^{8}=b a^{6}-t^{5}-a^{4}-b e t^{0}$

DETRANS ${ }^{8}=1$ SG.SBJ ${ }^{6}-\mathrm{TC}^{5}-$ PRES $^{4}-$ feel $^{0}$

'I understand.'

b. $\quad d a^{8}=b a^{6}-t^{5}-o^{4}-b^{3}-n^{2}-\boldsymbol{e} t^{0}$ (pronounced batomnet $<* d^{8}=b a^{6}-t^{5}-o^{4}-n^{2}-\boldsymbol{w e t} t^{0}$ )

DETRANS ${ }^{8}=1$ SG.SBJ ${ }^{6}-\mathrm{TC}^{5}-\mathrm{PAST}^{4}-\mathrm{TC}^{3}-$ PAST $^{2}-$ feel $^{\mathbf{0}}$

'I understood.'

Vajda (2004: 66-68) originally misinterpreted the various metathesized $b$ elements in position P3 as morphemes expressing lexical categories such as 'applicative', 'involuntary causative' or 'intensive', seeing them as etymologically derived from inanimate-class $b^{3}$. Even native speakers of Ket occasionally reanalyze thematic $b^{3}$ as inanimate-class agreement, replacing it by analogy with other object markers; Krejnovich (1968: 91) gives an example of such non-canonical forms, 
which exhibit multi-site object marking, since the P6 object markers are also present. Section 2 below will discuss other instances of reanalysis that actually did lead to permanent shifts in conjugation class.

Table 5 summarizes the three primary lexical position classes (shaded) and lexical morpheme categories (bold print) found in the Ket verb template.

\begin{tabular}{|c|c|c|c|c|c|c|c|c|c|}
\hline P8 & P7 & P6 & P5 & P4 & P3 & P2 & P1 & P0 & P-1 \\
\hline $\begin{array}{c}\mathrm{sbj} \text { agr } \\
\text { or } \\
\text { detrans } \\
d a=\end{array}$ & $\begin{array}{c}\text { incor- } \\
\text { porated } \\
\text { noun, } \\
\text { modifier, } \\
\text { or action } \\
\text { nominal }\end{array}$ & $\begin{array}{c}\text { obj } \\
\text { or } \\
\text { sbj } \\
\text { agr }\end{array}$ & $\begin{array}{c}\text { thema- } \\
\text { tic } \\
\text { conso- } \\
\text { nant } \\
(k, t, d, \\
q, h, n, \\
\eta, k d, \\
k t, n t, \\
\eta t)\end{array}$ & $\begin{array}{c}3 \text { anim } \\
\text { agr or } \\
\text { conj } \\
(s / i \sim a / o)\end{array}$ & $\begin{array}{c}3 \text { inan } \\
\text { agr } \\
\text { or } \\
\text { themat. } \\
b(<\mathbf{P 5} \\
*^{*} p \text { or } \\
\text { P0 } \\
\text { anlaut } \\
\left.*_{w} w\right)\end{array}$ & $\begin{array}{l}\text { aspect } \\
(\mathrm{n} \sim \mathrm{l})\end{array}$ & $\begin{array}{l}1,2 \text { agr } \\
\text { or } \\
\text { result } \\
\text { affix }\end{array}$ & $\begin{array}{c}\text { BASE } \\
\text { (verb } \\
\text { root or } \\
\text { lexical } \\
\text { aspect } \\
\text { marker }\end{array}$ & $\begin{array}{c}\text { anim } \\
\text { pl sbj } \\
\text { agr }\end{array}$ \\
\hline
\end{tabular}

Table 5.

Summary of lexical position classes and morphemes in Modern Ket finite verbs

As mentioned earlier, every verb has a 'formulaic stem'. There are the three core lexical positions P7-P5-P0 and any lexical affixes occupying positions P8, P3 and P1 in place of the agreement morphology usually found in these slots. Two additional pieces of information must also be included in the verb's lexical entry. First, tense-mood inflection involves an unpredictable choice of affix shapes in positions $\mathrm{P} 4$ and $\mathrm{P} 2$. The positions themselves are identical for most stems, but the combination of morphemes $-s / i$ or $a / o$ in $\mathrm{P} 4$ with $l$ or $n$ in $\mathrm{P} 2-$ is lexically idiosyncratic. Second, the positions used to express subject and object agreement cannot be predicted based on any overall semantic or formal pattern; therefore, they must be listed as part of the lexical entry, as well. This can be done by placing capital letters $\mathrm{S}$ and $\mathrm{O}$ in the appropriate position(s) in the stem formula or by placing a designation for agreement class such as $v t 1$ (transitive class I) or $v 5$ (intransitive class V) after the stem. Superscript numerals can specify position class, but this becomes unnecessary after one becomes more familiar with the verb structure. Here are three ways Ket verb stems might be listed in a dictionary:

(13) Different formalisms for listing the Ket stem meaning 'S leads O out':

a. Minimal formula: $\partial l a^{7}-k^{5}-a q^{0}(s / i l$ tense/mood class, transitive agreement II)

b. Extended formula (Kotorova and Nefedov 2015): $a l a^{7}-k^{5}-\left[s^{4}\right]-\left[l^{2}\right]-a q^{0}(v t 2)$

c. Maximal formula (this article): $S^{8}-a l a^{7}-O^{6}-k^{5}-\left(s^{4} / l^{2}\right)-a q^{0}-S_{P L}{ }^{-1}$ 
The minimal formula in (13a) contains only the three core lexical morphemes classes, with information about tense-mood and agreement class provided afterward. The extended formula used in Kotorova and Nefedov's (2015) Comprehensive Ket Dictionary includes all lexically fixed morpheme shapes, including detransitive P8, thematic P3, and resultative P1, as well as the P4 and P2 tense-mood shapes, which appear in square brackets if they occur only in some forms; information about agreement class is given outside the formula, and the reader must become intimately familiar with the positions occupied by subject and object markers in each of the five productive intransitive agreement types and three transitive agreement types. The maximal approach lists agreement positions and tense-mood affix shapes in the stem itself. This approach is used in Vajda \& Werner's (in preparation) Etymological Dictionary of the Yeniseian Languages, though without superscript numbers. Because the P7 incorporate is syllabic and the P5 thematic consonant is not, the position of agreement markers is discernable even without numbering. The present article marks position class explicitly to help explain basic Ket verb structure as clearly as possible. ${ }^{1}$

Each of these formalisms has its merits. The extended formula (13b) is well suited for a synchronic dictionary, while the maximal formula (13c) is useful in an etymological dictionary where finite verb formulas appear under entries headed by a lexical root. The architecture of stem formulas will become clearer after tense-mood marking and subject/object agreement are discussed more fully in the next section.

\section{The templatic expression of inflectional categories and lexical semantic patterns}

Despite its formal exuberance, the Ket verb contains only two inflectional subsystems: tense-mood marking and subject/object agreement. Let us look at each in turn and identify the idiosyncrasies associated with them that must be listed in the verb's lexical entry, before moving on to lexical semantics in 2.3.

\subsection{Tense-mood marking}

Stems regularly inflect to distinguish three synthetic tense-mood forms: past indicative, non-past indicative (interpretable as either present or future tense) and

\footnotetext{
${ }^{1}$ I thank Andrey Nefedov for suggestions on the wording of this section, and for helping proofread the article.
} 
imperative (limited to stems expressing intentional actions). Other grammatical tense-mood-aspect categories can be expressed by pre-verbal particles (as 'future action', ba 'habitual past action', sim 'conditional', etc.). Formally, tense-mood inflection is based on two interacting sets of affixes in position P4 (conjugation markers of unknown original meaning) and P2 (originally aspect markers). Table 6 highlights the template's tense-mood position classes:

\begin{tabular}{|c|c|c|c|c|c|c|c|c|c|}
\hline P8 & P7 & P6 & P5 & P4 & P3 & P2 & P1 & P0 & P-1 \\
\hline $\begin{array}{l}\text { sbj } \\
\text { pers. } \\
\text { agr or } \\
\text { detrans } \\
\text { marker }\end{array}$ & $\begin{array}{l}\text { incor- } \\
\text { porate }\end{array}$ & $\begin{array}{l}\text { obj } \\
\text { or } \\
\text { sbj } \\
\text { agr }\end{array}$ & $\begin{array}{l}\text { the- } \\
\text { matic } \\
\text { cons } \\
(k, t \text {, } \\
d, \\
\text { etc. })\end{array}$ & \begin{tabular}{|c|}
3 \\
anim \\
agr or \\
conj \\
s/i $\sim$ alo, \\
(rarely $q)$
\end{tabular} & $\begin{array}{l}3 \text { inan } \\
\text { agr } \\
\text { or } \\
\text { themat. } \\
b\end{array}$ & $\begin{array}{c}\text { tense- } \\
\text { mood } \\
n \sim l, \\
(\text { rarely } \\
j)\end{array}$ & $\begin{array}{c}1,2 \mathrm{sbj} \text { or } \\
\text { obj agr or } \\
\text { result } \\
\text { affix }\end{array}$ & BASE & $\begin{array}{l}\text { anim pl } \\
\text { sbj agr }\end{array}$ \\
\hline
\end{tabular}

Table 6. Tense-mood-aspect related positions in the Ket verb template

The template's historical development cannot be understood without taking metathesis into account (Vajda 2013). We have already seen how metathesis led to the rise of thematic $b$ in position P3. The "authentic" inanimate-class agreement marker $b^{3}$ itself once occupied $\mathrm{P} 4$, forming a single position class with the $3^{\text {rd }}$ person animate-class agreement markers. However, it metathesized ahead of non-past $a$ and past-tense $o$ due to the same phonological rule that sporadically switched labial and non-labial segments elsewhere (cf. non-metathesized Southern Ket qoqpun 'cuckoo bird' and metathesized Central and Northern Ket qopqun 'cuckoo bird'). Labial metathesis did not occur in Kott, where the template retains its original ordering of $3^{\text {rd }}$ person agreement followed by tense-mood-aspect-transitivity affixes:

(14) Kott verbs with inanimate-class agreement marker in original position P4

a. $\boldsymbol{b}^{4}-a^{3}-p i^{0}$

3INAN.SBJ ${ }^{4}$-PRES ${ }^{3}-$ grow $^{0}$

'It grows.'

b. $\quad m^{4}-a^{3}-n^{2}-a^{1}-p i^{0}$

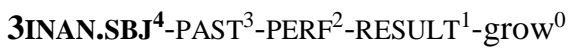

'It grew up.'

(15) Ket verbs with inanimate-class $b$ metathesized forward into position P3

a. $\quad a^{4}-b^{3}-a^{1}-t i j^{0}$

PRES $^{4}$-3INAN.SBJ ${ }^{3}$-INTRANS ${ }^{1}$-grow $^{0}$

'It grows.' 
b. $\quad o^{4}-b^{3}-l^{2}-a^{l}-t i j^{0}$

PAST ${ }^{4}$-3INAN.SBJ ${ }^{3}$-IMPERF ${ }^{2}$-INTRANS ${ }^{1}$ - grows $^{0}$

'It was growing.'

More is said about metathesis in section 2.2, as it has complicated the Ket agreement system in other ways too.

The locus of grammatical tense-mood marking in Modern Ket is thus the linearly separate position classes $\mathrm{P} 4$ and $\mathrm{P} 2$. The P4 slot usually contains one of two conjugation marker forms: $a^{4}$ or $s^{4}$. Conjugation marker $a^{4}$ regularly labializes to $o^{4}$ in past-tense forms, but remains $a^{4}$ in non-past and imperative forms. Conjugation marker $s^{4}$ never appears in past indicative or imperative forms, being replaced by $i$ or $\varnothing$ whenever a P2 consonant appears ${ }^{2}$. This often occurs in non-past indicative forms, as well, since the phonetic realization of $s^{4}$ appears to be subject to complicated rules (Vajda 2004: 74-76) that are not yet fully understood. There is no discernable functional difference between $a / o$ and $s / i / \varnothing$ verbs. The P4 allomorph $s \sim$ $i \sim \varnothing \sim a / o$ characteristic of a given stem developed through complex morphophonemic interactions with the surrounding affixes, processes that are no longer obvious. Also, when an animate-class agreement marker occupies P4, it normally cancels out or merges with the conjugation marker vowel in the same position. $^{3}$

The P2 slot contains consonants that originally marked aspect. Most pastindicative and imperative forms have either $n^{2}$ or $l^{2}$, which interact with $a / o^{4}$ or $i / \varnothing^{4}$ to form the inflectional tense-mood system of Modern Ket. Before most vowelinitial bases, imperative forms add $d$. The resulting combinations of $n d$ and $l d$ that appear before vowel-initial bases are counted as part of position class P2.

(16) Examples of imperative forms with $d^{2}$

a. $\quad a^{4}-n d^{2}-i^{0}$

$\mathrm{IMP}^{4 / 2}$-sharpen ${ }^{0}$

'Sharpen it!'

\footnotetext{
${ }^{2}$ It is not always clear when $i$ should be treated as a tense-mood marker occupying position $\mathrm{P} 4$ and when it is epenthetic. The present article treats it as $i^{4}$ under word stress or when it is linearly separated from the P2 consonant. In other cases, it is included in P2 as $i l^{2}$ or $i n^{2}$.

${ }^{3}$ Rarely, the agreement marker and conjugation marker preserve the original Proto-Yeniseian (and presumably pre-Ket) ordering: $d^{8}-u l^{7}-d^{5}-a \eta^{4}-s^{3}-k \partial \eta^{0}$ 'he washes them' (<3MASC.SBJ ${ }^{8}-$ water ${ }^{7}$-TC $^{5}$-3ANIM.PL.SBJ ${ }^{4}$-PRES ${ }^{3}$-wash ${ }^{0}$ ). See Vajda (2001: 434-435) for more examples, though the phenomenon was not understood at the time.
} 
b. $\quad i^{4}-l d^{2}-i l^{0}$

$\mathrm{IMP}^{4 / 2}-\operatorname{sing}^{0}$

'Sing!'

Imperative $d$ is vestigial in Modern Ket, appearing only before bases that were vowel-initial in Proto-Yeniseian. The distribution of $l$ and $n$ across past-indicative and imperative forms is normally parallel. If a stem's past-indicative forms have $n$, then the imperative also has $n$ (or $n d$ ). If the past-indicative has $l$, the imperative also has $l$ (or $l d$ ). Non-past indicative forms, by contrast, have no P2 marker at all (except for some forms of the irregular stem 'know', which has $l^{2}$ in past and non-past forms alike: $i t^{7}-a^{4}-l^{2}-a m^{0}$ 'he knows / he knew'). The choice between $n^{2}$ and $l^{2}$ partly follows lexical aspect. P2 $n$ appears in many stems denoting single complete actions or changes of state, a vestige of its original perfective aspect marking function. P2 $l$ appears in the past tense of all stems that specifically denote multiple actions or static situations, a vestige of its former function of marking imperfective aspect. Verbs that express a state resulting from a prior action (called 'resultatives', 'stativeresultatives' or 'perfective-statives') likewise mark past tense with $l^{2}$. P2 $n$ never appears in stems that specifically denote static states, ongoing activity, or repeated action. However, some stems with $l^{2}$ express single complete actions or express either single complete action or repeated action, depending on context. It is thus not possible to say the P2 consonants mark grammatical aspect in Modern Ket. The choice of P2 consonant for past indicative and imperative is lexically fixed and must be listed in the stem formula. A tiny number of stems do show paradigmatic alternations between perfective $n^{2}$ and imperfective $l^{2}$ to signal single vs. multiple action, but this too is an idiosyncrasy of the stems in question and also must be listed as part of their lexical entry. A few common stem types have no P2 marker at all and signal tense solely by alternating non-past $a$ with past-tense $o$ in slot P4 (and sometimes in the P0 base vowel, as well, displaying a rare instance of Ket vowel harmony).

Most stems belong to one of five productive tense-mood classes, which must be specified in the verb's lexical entry:

(17) Tense-mood class $s / i n(=i / n) \quad\left(\right.$ stems with $\boldsymbol{s}^{4}$ and $\boldsymbol{n}^{2}$ or only $\left.[\boldsymbol{i}] \boldsymbol{n}^{2}\right)$

Example stem:

$S^{8}-O^{6}-k^{5}-\left(s^{4} / n^{2}\right)-d o q^{0}-S_{P L}^{-1}$

$\mathrm{SBJ}^{8}$-OBJ ${ }^{6}$-toward ${ }^{5}$-(tense $/$ mood $\left.^{4 / 2}\right)$-jump ${ }^{0}$-ANIM.PL.SBJ ${ }^{-1}$

' $\mathrm{S}$ attacks $\mathrm{O}$ '

Non-past indicative: $\quad d^{8}-a^{6}-k^{5}-s^{4}-d o q^{0} \quad$ 'he attacks him' 
Past indicative: $\quad d^{8}-a^{6}-k^{5}-i n^{2}-d o q^{0} \quad$ 'he attacked him'

Imperative: $\quad a^{6}-k^{5}-i n^{2}-d o q^{0} \quad$ 'attack him!'

(18) Tense-mood class $s / i l(=i / l) \quad\left(\right.$ stems with $s^{4}$ and $\boldsymbol{l}^{2}$ or only $[\boldsymbol{i}] \boldsymbol{l}^{2}$ )

Example stem: $\quad S^{8}-\operatorname{nan}^{7}-\left(s^{4} / l^{2}\right)-$ bed $^{0}-S_{P L}{ }^{-1}$

$\mathrm{SBJ}^{8}$-bread ${ }^{7}$-(tense $/$ mood $^{4 / 2}$ )-make ${ }^{0}$-ANIM.PL.SBJ ${ }^{-1}$

'S makes bread'

Non-past indicative: $\quad d a^{8}=n a n^{7}-s^{4}-$ ibed $^{0} \quad$ 'she makes bread'

Past indicative: $\quad d a^{8}=n a n^{7}-l^{2}-i b e d^{0} \quad$ 'she maked bread'

Imperative: $\quad n a n^{7}-i l^{2}$-get ${ }^{0} \quad$ 'bake bread!'

(19) Tense-mood class $\boldsymbol{a} / \boldsymbol{o n}$ (stems with $\boldsymbol{a} / \boldsymbol{o}^{4}$ and $\boldsymbol{n}^{2}$ )

Example stem: $\quad S^{8}-k^{5}-\left(a / o^{4} n^{2}\right)-q u t^{0}-S_{P L}{ }^{-1}$

$\mathrm{SBJ}^{8}$-up ${ }^{5}$-(tense $/$ mood $^{4 / 2}$ )-go ${ }^{0}$-ANIM.PL.SBJ ${ }^{-1}$

'S ascends, goes up'

Non-past indicative:

$$
\begin{array}{ll}
d \partial^{8}=k^{5}-\boldsymbol{a}^{4}-q u t^{0} & \text { 'she goes up' } \\
d a^{8}=k^{5}-\boldsymbol{o}^{4}-\boldsymbol{n}^{2}-q u t^{0} & \text { 'she went up'} \\
k^{5}-\boldsymbol{a}^{4}-\boldsymbol{n}^{2}-q u t^{0} & \text { 'go up!' }
\end{array}
$$

Past indicative:

Imperative:

(20) Tense-mood class $\boldsymbol{a} / \boldsymbol{o l}$ (stems with $\boldsymbol{a} / \boldsymbol{o}^{4}$ and $\boldsymbol{l}^{2}$ )

Example stem: $\quad S^{8}-O^{6}-k^{5}-\left(a / o^{4} l^{2}\right)-d o^{0}-S_{P L}{ }^{-1}$

$\mathrm{SBJ}^{8}$-toward ${ }^{5}$-(tense $/$ mood $^{4 / 2}$ )-look ${ }^{0}$-ANIM.PL.SBJ ${ }^{-1}$

'S looks, stares at $\mathrm{O}$ '

Non-past indicative:

$$
\begin{array}{ll}
d^{8}-a^{6}-k^{5}-\boldsymbol{a}^{4}-d o^{0} & \text { 'he looks at him' } \\
d^{8}-a^{6}-k^{5}-\boldsymbol{o}^{4}-\boldsymbol{l}^{2}-d o^{0} & \text { 'he looked at him' } \\
a^{6}-k^{5}-\boldsymbol{a}^{4}-\boldsymbol{l}^{2}-d o^{0} & \text { 'look at him!' }
\end{array}
$$

(21) Tense-mood class $\boldsymbol{a} / \boldsymbol{o}$ (stems with $\boldsymbol{a}^{4}$ becoming past-tense $\boldsymbol{o}^{4}$ and no P2 indicated)

Example stem: $\quad$ nanbed $d^{7}-S^{6}-k^{5}-\left(a / o^{4}\right)-q a n \sim q o n^{0}$

bread.make ${ }^{7}-\mathrm{SBJ}^{6}-\mathrm{TC}^{5}$-(tense $/$ mood $^{4 / 2}$ )-INCEPT ${ }^{0}$

'S starts making bread'

Non-past indicative: nanbed ${ }^{7}-i^{6}-k^{5}-\boldsymbol{a}^{4}-q a n^{0} \quad$ 'she starts making bread'

Past indicative: nanbed $d^{7}-i^{6}-k^{5}-\boldsymbol{o}^{4}-q o n^{0} \quad$ 'she started making bread

Imperative: $\quad$ nanbed $d^{7}-k u^{6}-k^{5}-\boldsymbol{a}^{4}-q a n^{0} \quad$ 'start making bread!' 
A few stems contain $j^{2}$, which appears to be derived morphophonemically from $n^{2}$ and sometimes alternates with it (22a). And $q^{2}$ appears in the past tense of a few stems meaning 'kill' $(22 b)^{4}$.

(22) Irregular past-tense marker shapes

a. $\quad d^{8}-a t^{7}-b^{3}-i \boldsymbol{j}^{2}-a q^{0} \sim d^{8}-a t^{7}-b^{3}-\mathbf{i n} \mathbf{n}^{2}-d a q^{0}$

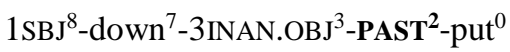

'I poured it.'

b. $\quad d^{8}-a^{4}-\boldsymbol{q}^{2}-e j^{0}$ 'I killed him'

$1 \mathrm{SBJ}^{8}$-3MASC.SG.OBJ ${ }^{4}$-PAST ${ }^{2}$-kill ${ }^{0}$

'I killed him.'

The unpredictable appearance of $j^{2}$ or $q^{2}$ must be listed in the stem formula, just as the distribution of $n^{2}$ - and $l^{2}$ - is no longer fully predictable based on lexical aspect.

There are two key points to summarize regarding tense-mood marking. First, from the perspective of synthetic inflectional morphology, Ket has only three tensemood forms - past indicative, non-past-indicative, and imperative - despite the template's formal complexity. Second, the position of tense-mood inflections in the template is predictable $(\mathrm{P} 4+\mathrm{P} 2)$, but the inflection shapes themselves are idiosyncratic, forming five productive tense-mood classes. These cannot properly be called 'conjugations' because they minimally interact with the agreement morphology.

\subsection{Agreement marking}

The situation with Ket agreement is the mirror opposite of the tense-mood system. Tense-mood inflections have lexically unpredictable forms that occupy predictable positions. Agreement morpheme shapes are predictable, but their position classes are not and must be specified in the verb's lexical entry.

Ket verb-internal subject and object markers distinguish agreement along the following three parameters. First, there is a distinction in person $\left(1^{\text {st }}, 2^{\text {nd }}\right.$ or $\left.3^{\text {rd }}\right)$ that

\footnotetext{
${ }^{4}$ Historically, past-tense $q(<* q o)$ was conjugation marker that alternated with $* s i$ in position $\mathrm{P} 3$, which is why the $\mathrm{P} 4$ agreement markers $-a$ and $-a \eta$ do not labialize preceding it. However, because $q$ fulfills the same past-tense function as $l^{2}$ and $n^{2}$ in Modern Ket, it is best treated as occupying P2.
} 
encompasses all subjects and objects. Second, there is a distinction between singular and plural. Finally, third person distinguishes noun class. Person, number and class agreement interact in the following way: plural is distinguished for all animate-class subjects and objects. The noun class of third person subjects and objects interacts with number to create four subcategories: feminine singular animate, masculine singular animate, plural animate, and inanimate (normally without distinguishing singular from plural). Table 7 summarizes these functions across the position classes where they are expressed:

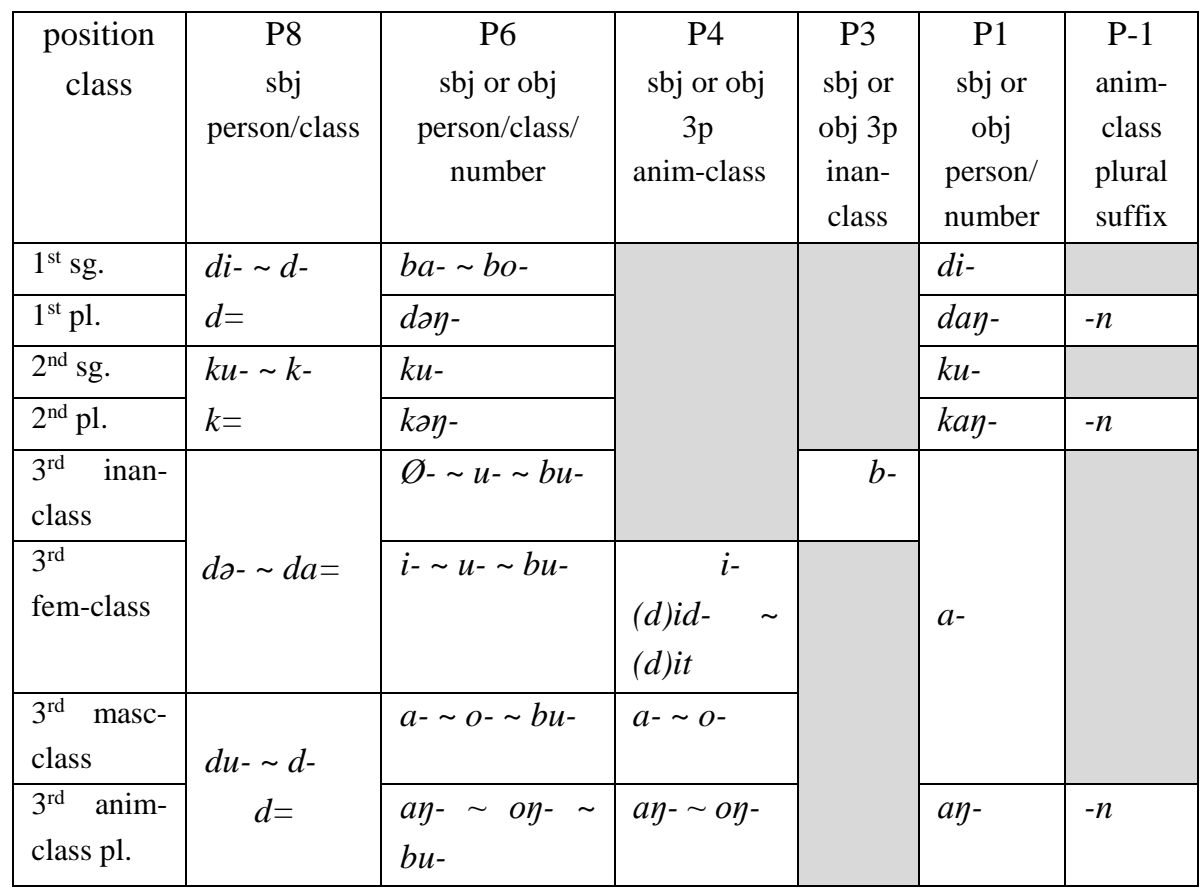

Table 7.

Position, form and agreement functions of Ket subject and object markers

Although six position classes out of ten are involved in agreement, Ket has no morphologically trivalent verbs. In terms of verb-internal agreement morphology, Ket verb stems are avalent, monovalent or bivalent (Nefedov, Malchukov and Vajda 2010 and 2011). 
(23) Examples of avalent (a), monovalent (b), and bivalent (c) Ket verb stems

a. $\quad s i l^{7}-d^{5}-\left(a / o^{4}\right)-b^{3}-q a n^{0}$ 'summer begins'

$s i l^{7}-d^{5}-o^{4}-b^{3}-q a n^{0}$ (pronounced in Southern Ket as sildovon)

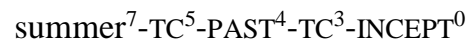

'Summer began.'

b. $\quad S^{8}=s i l^{7}-h^{5}-\left(a / o^{4} n^{2}\right)-a q^{0}-S_{P L}{ }^{-1} \quad$ 'S spends (one) summer'

$\boldsymbol{d}^{8}=s i l^{7}-h^{5}-o^{4}-n^{2}-a q^{0}$ (pronounced in Southern Ket as silunaq)

$1 \mathrm{SBJ}^{8}$-summer ${ }^{7}-\mathrm{TC}^{5}$-PAST ${ }^{4 / 2}$-spend ${ }^{0}$

'I spent a summer.'

c. $\quad S^{8}=$ silaqy $^{7}-q^{5}-\left(a / o^{4} l^{2}\right)-\boldsymbol{O}^{4 / 3 / 1}-d a^{0}-S_{P L}{ }^{-1}$ 'S makes / lets O spend the summers' $\boldsymbol{d}^{8}=\operatorname{silaq\eta }^{7}-q^{5}-\boldsymbol{o}^{4}-l^{2}-d a^{0}-n^{-1}$

$\mathbf{1 S B J}^{8}=$ spend.summer ${ }^{7}-\mathrm{TC}^{5}$-3MASC.SG.OBJ ${ }^{4}$-PAST ${ }^{2}$-TRANS.MOM ${ }^{0}-$ SANIM.PL $^{-1}$

'They used to make him spend the summer (somewhere).'

Nor do agreement positions predictably distinguish semantic roles, in contrast to interpretations by Belimov (1991), Reshetnikov and Starostin (1995), and Butorin (1995). Modern Ket has five productive intransitive classes, each with a different position-class expression of subject agreement. These patterns were called 'actant conjugations' in Vajda (2001, 2003, 2004), who gave them names such as 'absolutive conjugation' or 'inactive conjugation', which created the misleading impression that agreement class membership was based on functional differences in valency. Here they are called simply 'agreement classes', as they resemble IndoEuropean conjugation classes, except that Ket involves differences in position class whereas Indo-European agreement suffixes occupy the same position in every stem. Some Ket agreement classes involve multi-site subject marking, while others mark the subject only once.

(24) The five productive Ket intransitive agreement classes

i. Intransitive class I ( $v 1)$ : (animate-class subject person ${ }^{8}$ and plural $^{-1}$ )

a. $\quad d^{8}-e s^{7}-o^{4}-l^{2}-i j^{0}-n^{-1}$

$3 \mathrm{SBJ}^{8}$-into.open.space ${ }^{7}$-PAST ${ }^{4 / 2}$-call ${ }^{0}$-ANIM.PL.SBJ ${ }^{-1}$

'They shouted.'

b. $\quad d u^{8}-n^{2}-q o^{0}-n^{-1}$

$3 \mathrm{SBJ}^{8}$-PAST ${ }^{2}$-die ${ }^{0}$-ANIM.PL.SBJ ${ }^{-1}$

'They died.' 
c. $\quad d^{8}-i k d a^{7}-k^{5}-l^{2}-a q^{0}-n^{-1}$

$3 \mathrm{SBJ}^{8}$-forest.to.river ${ }^{7}-\mathrm{TC}^{5}$-PAST ${ }^{2}$-go ${ }^{0}$-ANIM.PL.SBJ ${ }^{-1}$

'They made a round trip to the riverbank (lasting several days).'

d. $\quad d^{8}=k \partial t^{7}-h^{5}-o^{4}-n^{2}-a q^{0}-n^{-1}$

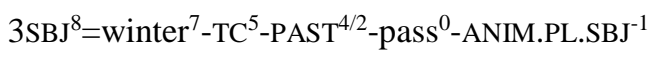

'They spent the winter.'

ii. Intransitive class II ( $v 2)$ : (any subject person, class, number marked in P6)

a. $\quad b a^{6}-k^{5}-s^{4}-s a l^{0}$

1SG.SBJ ${ }^{6}-\mathrm{TC}^{5}$-PRES ${ }^{4}$-spend.night ${ }^{0}$

'I spent the night.'

b. $\quad$ intip $p^{7}-b o^{6}-l^{2}-a^{1}-b e d^{0}$

puppy $^{7}-1$ SG.SBJ ${ }^{6}-$ PAST $^{2}-$ RESULT $^{1}$ - possess $^{0}$

'I had a puppy.'

c. $\quad \dot{i} s^{7}-a \eta^{6}-k^{5}-o^{4}-q a n^{0}$

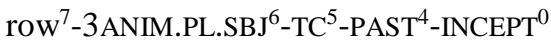

'They started rowing.'

iii. Intransitive class III (v3): (multi-site subject marking in P8, P6, and P-1)

a. $\quad d^{8}-i k d a^{7}-b u^{6}-t^{5}-l^{2}-a q^{0}-n^{-1}$

$3 \mathrm{SBJ}^{8}$-to.river ${ }^{7}-3 \mathrm{SBJ}^{6}-\mathrm{TC}^{5}$-PAST ${ }^{2}$-go ${ }^{0}$-ANIM.PL.SBJ ${ }^{-1}$

'They made a quick round trip to the riverbank.'

b. $\quad d^{8}=b u^{6}-t^{5}-o^{4}-l^{2}-o k^{0}-n^{-1}$

$3 \mathrm{SBJ}^{8}=3 \mathrm{SBJ}^{6}-\mathrm{TC}^{5}-\mathrm{PAST}^{4 / 2}$-jump ${ }^{0}$-ANIM.PL.SBJ ${ }^{-1}$

'They shuddered.'

c. $\quad d^{8}=b u^{6}-\eta^{5}-l^{2}-u q o^{0}-n^{-1}$

$3 \mathrm{SBJ}^{8}=3 \mathrm{SBJ}^{6}-\mathrm{TC}^{5}-\mathrm{PAST}^{2}-$ look $^{0}$-ANIM.PL.SBJ ${ }^{-1}$

'They looked (searched for something),'

iv. Intransitive class IV (v4): (multi-site marking of anim.-class subjects in P8 $+\mathrm{P} 1$ )

(multi-site marking of inan.-class subjects in P3 + P1)

a. $\quad d^{8}-i k d a^{7}-o^{4}-n^{2}-a \eta^{1}-d a q^{0}$

$3 \mathrm{SBJ}^{8}$-to.river ${ }^{7}$-PAST ${ }^{2}-3$ ANIM.PL.SBJ ${ }^{1}-$ go $^{0}$

'They went to the river (and stayed there).' 
b. $\quad d^{8}=d^{5}-o^{4}-l^{2}-a \eta^{1}-d u n^{0}$

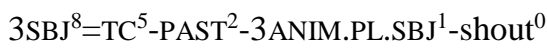

'They gave a shout.'

c. $\quad d^{8}-o^{4}-l^{2}-a \eta^{1}-t i j^{0}$

$3 \mathrm{SBJ}^{8}$-PAST ${ }^{4 / 2}-3$ ANIM.PL.SBJ ${ }^{1}$-grow ${ }^{0}$

'They grew up.'

v. Intransitive class V (v5): (3animate subject ${ }^{4}, 1^{\text {st }}$ or $2^{\text {nd }}$ person subject ${ }^{1}$ )

(3inanimate subject ${ }^{3}$ )

a. $\quad i^{7}-d i^{1}-b e d^{0}$

day $^{7}-1$ SG.SBJ ${ }^{1}$-spend ${ }^{0}$

'I spend the day.'

b. $\quad t i p^{7}-i l^{2}-d i^{1}-b e d^{0}$

$\operatorname{dog}^{7}$-PAST ${ }^{2}-1$ PL.SBJ ${ }^{1}$-possess ${ }^{0}$

'I had a dog.'

c. $u s^{7}-o \eta o^{4}-n^{2}-d e n^{0}$

sleep ${ }^{7}$-3ANIM.PL.SBJ ${ }^{4}$-PAST ${ }^{2}$-event.occurs ${ }^{0}$

'They fell asleep.'

Stems that use intransitive class $\mathrm{V}$ (v5) to mark animate-class subjects are logically precluded from having inanimate-class subjects. Inanimate-class marking in this class occurs in stems, that mark their animate-class subjects according to the pattern of intransitive class I $(v l)$.

(25) Agreement class dichotomy between animate-class and inanimate-class subjects

i. Intransitive class I $(v l)$ : (animate-class subject person ${ }^{8}$ and plural $\left.^{-1}\right)$

$$
\begin{aligned}
& d^{8}-i l^{2}-\operatorname{loq} \eta^{0}-n^{-1} \\
& 3 \mathrm{SBJ}^{8}-\mathrm{PAST}^{2} \text {-shake }{ }^{0} \text {-ANIM.PL.SBJ }{ }^{-1} \\
& \text { 'They (animate-class) shook.' }
\end{aligned}
$$

ii. Intransitive class V $(v 1)$ : (inanimate-class subject ${ }^{3}$ )

$$
\begin{aligned}
& b^{3}-i l^{2}-l o q \eta^{0} \\
& \text { 3INAN.SBJ }{ }^{3}-\text { PAST }^{2} \text {-shake }{ }^{0} \text {-ANIM.PL.SBJ }
\end{aligned}
$$

'They (inanimate-class things) shook.' or 'It shook.' 
Intransitive class $\mathrm{V}$ stems with inanimate-class subjects could therefore instead be interpreted as belonging to inanimate-class I. This, in fact, would corresponds to their historical development and would also parallel the class-based dichotomy found in intransitive class IV stems. (Stems belonging to intransitive classes II or III have no positional dichotomy between their animate-class and inanimate-class subjects.) Under such an interpretation, intransitive class V would contain only animate-class verbs expressing static conditions or changes of state that are logically limited to animate-class participants (such as 'wake up', 'own', 'get sleepy', etc.). In any case, stems with such meanings are not restricted to intransitive class I and can be found in the other four intransitive agreement classes as well, so the semantic correlation here is only partial.

Transitive stems are divided into three productive agreement classes (see Vajda 2001, 2004, 2009; Georg 2007).

(26) The three productive Ket transitive agreement classes

i. Transitive class I $(v t l): \quad\left(\right.$ subject person ${ }^{8}$, subject plural $\left.^{-1}\right)$

(3animate object ${ }^{4}, 3$ inanimate object ${ }^{3}, 1 \mathrm{p}$ or $2 \mathrm{p} \mathrm{object} \mathrm{t}^{1}$ )

a. $\quad d^{8}=b a k d e \eta^{7}-q^{5}-a^{4}-d i^{1}-d a^{0}-n^{-1}$

$3 \mathrm{SBJ}^{8}=$ pull $^{7}$-INCEPT ${ }^{5}$-PRES ${ }^{4}-1$ SG.OBJ ${ }^{1}$-ITER.TRANS ${ }^{0}$-ANIM.PL.SBJ ${ }^{-1}$

'They frequently pull me.' or 'They frequently start pulling me.'

b. $\quad d^{8}-i n^{2}-d i^{1}-t e k^{0}-n^{-1}$

$3 \mathrm{SBJ}^{8}$-PAST ${ }^{2}$-1SG.OBJ ${ }^{1}$-hit.endwise ${ }^{0}$-ANIM.PL.SBJ ${ }^{-1}$

'They beat me (past tense, single event).'

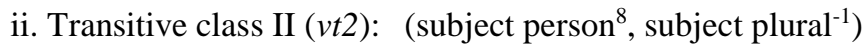

(person, class and number of any object marked in P6)

a. $\quad d^{8}=b a k d e \eta^{7}-b o^{6}-k^{5}-a^{4}-b e d^{0}-n^{-1}$

$3 \mathrm{SBJ}^{8}=$ pull ${ }^{7}-1 \mathrm{SG} . \mathrm{OBJ}^{6}-\mathrm{TC}^{5}$-PRES ${ }^{4}$-ITER.TRANS ${ }^{0}$-ANIM.PL.SBJ ${ }^{-1}$

'They frequently pull me.' or 'They are pulling me (process).'

b. $\quad d^{8}=d o n^{7}-b a^{6}-h^{5}-i l^{2}-t e k^{0}-n^{-1}$

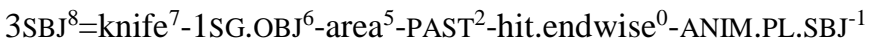

'They stabbed me (once).'

iii. Transitive class III (vt3): (multi-site subject marking in P8, P6, and P-1)

(3animate object ${ }^{4}, 3$ inanimate object ${ }^{3}, 1 \mathrm{p}$ or 2 object $^{1}$ ) 
a. $\quad d^{8}-a k a^{7}-b u^{6}-k^{5}-d i^{1}-q o s^{0}-n^{-1}$ $3 \mathrm{SBJ}^{8}$-river.to.forest ${ }^{7}-3 \mathrm{SBJ}^{6}-\mathrm{TC}^{5}-1 \mathrm{SG} . \mathrm{OBJ}^{1}$-take ${ }^{0}$-ANIM.PL.SBJ ${ }^{-1}$

'They take me into the forest.'

b. $\quad d^{8}=b u^{6}-t^{5}-a^{4}-b^{3}-d a q^{0}-n^{-1}$

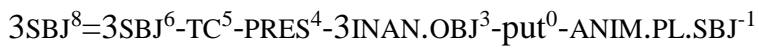

'They pull it out.'

A handful of stems have unproductive agreement patterns (Vajda 2004: 70). The origins of Ket agreement classes - both productive and unproductive - are complex, involving factors such as reanalysis and metathesis, and generally having nothing directly to do with valency (Vajda 2013). Vajda (in press 2) implicates the partial phonological erosion of the original P1 subject markers and their replacement by P8 subject markers, leading to multi-site subject marking in stems where the P1 markers happened to remain. Another factor was metathesis between agreement markers and the stem's P5 thematic consonant. In some stems, object markers that originally occupied position P6 metathesized to the right of the P5 marker, assuming positions $\mathrm{P} 4, \mathrm{P} 3$ or P1, depending on person and class. In other stems, subject markers that originally occupied P4, P3 or P1 metathesized into position P6. Because metathesis involved a phonological trigger (adjacent segments differing in $+/$ - labial), the resulting agreement classes do not pair up with distinctions in semantic or syntactic valency. A final complication involved sporadic reanalysis of morphemes across position classes. For example, in verbs meaning 'gulp down', the incorporate $b u \eta^{7}$ 'lump' was reanalyzed as the subject marker $b u^{6}$ followed by thematic consonant $\eta^{5}$.

(27) Reanalysis of incorporate causing shift in agreement class from $v t 1$ (a) to vt3 (b)

a. Original structure

$* d^{8}=\boldsymbol{b} \boldsymbol{u} \boldsymbol{y}^{7}-t^{5}-b^{3}-i l^{2}-d o p^{0}$

$* 3 \mathrm{SBJ}^{8}=$ lump $^{7}$-down ${ }^{5}$-3INAN.OBJ ${ }^{3}$-PAST ${ }^{2}$-injest ${ }^{0}$

'He (anim.-class bird) gulped it down.'

b. Reanalyzed structure

$d^{8}=\boldsymbol{b} \boldsymbol{u}^{6}-\boldsymbol{y} / t^{5}-b^{3}-i l^{2}-d o p^{0}$

$3 \mathrm{SBJ}^{8}=\mathbf{3 S B J}^{\mathbf{6}}$-TC/down ${ }^{5}$-3INAN.OBJ ${ }^{3}-\mathrm{PAST}^{2}$-injest ${ }^{0}$

'He (anim.-class bird) gulped it down.'

c. Replacement by other agreement markers

$d^{8}=\boldsymbol{b} \boldsymbol{a}^{6}-\boldsymbol{y} / t^{5}-b^{3}-i l^{2}-d o p^{0}$

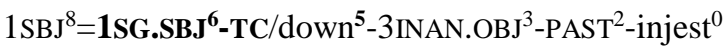

'I gulped it down.' 
Only some cases of multi-site subject marking arose in this way, though all instances of thematic $\eta^{5}$ appear to derive from this kind of reanalysis, in contrast to the interpretation in Vajda (2003: 75), where a futile attempt was made to assign them semantic etymologies.

To summarize, Modern Ket agreement classes, however they are called, must be specified in the stem formula or notated in parentheses afterward. Not doing so would omit a core element of the verb's lexical entry. A second key point is that the Ket verb is strongly head-marking. The subject and object are somehow distinguished from one another inside the verb form, while the verb-external subject and object noun phrases themselves are never morphologically marked.

\subsection{Lexical typology}

As argued by Werner (1997 and elsewhere), Ket is basically a nominativeaccusative language, with certain active typological traits, such as the positional contrast between animate- and inanimate-class marking observed in many intransitive stems. Otherwise, the various strategies for marking the subject or object lack a clear semantic basis. Syntactic valency is an obligatory lexical category. Also, Ket has no labile verbs. Avalent, monovalent, and bivalent stems with logically related meanings always differ in terms of the lexical morpheme configuration in P7-P5-P0, and not simply in the presence or absence of the agreement markers themselves. There are rather few derivational techniques for raising or lowering valency (Vajda 2015) and all of them are highly constrained lexically. Noun incorporation is restricted to a handful of bases. The base bed' 'make' freely incorporates its object, but most bases cannot incorporate nouns at all or incorporate only a few specific object nouns.

(28) Verb phrase without (a) and with (b) object incorporation

a. bu asl $d^{8}=b^{3}-i l^{2}-b e d^{0}$

he ski $3 \mathrm{SBJ}^{8}=3 \mathrm{INAN}^{-\mathrm{OBJ}^{3}}{ }^{3} \mathrm{PAST}^{2}-$ make $^{0}$

'He made a ski.'

b. $\quad d^{8}-a s l^{7}-i l^{2}-b e d^{0}$

$3 \mathrm{SBJ}^{8}-\mathrm{ski}^{7}-\mathrm{PAST}^{2}-\mathrm{make}^{0}$

'He made a ski.'

The bases $t e d^{0}$ 'hit endwise' and $k i t^{0}$ 'rub' can incorporate their instrument, but not their direct object (Vajda, in press 1). No other bases permit transitivity raising via instrument incorporation. 
(29) Verb phrase without (a) and with (b) instrument incorporation

a. ke'd tīb sal-as $d^{8}-a^{6}-t^{5}-a^{4}-k i t^{0}$ person dog tobacco-INSTR 3 SBJ $^{8}$-3MASC.SG.OBJ ${ }^{6}-\mathrm{TC}^{5}$-PRES $^{4}-\mathrm{rub}^{0}$ 'The man rubs the dog with tobacco $\sim$ rubs tobacco on the dog.'

b. ke'd tīb $d^{8}=s a l^{7}-a^{6}-t^{5}-a^{4}-k i t^{0}$ person dog $3 \mathrm{SBJ}^{8}=$ tobacco $^{7}-3$ MASC.SG.OBJ ${ }^{6}-\mathrm{TC}^{5}-\mathrm{PRES}^{4}-\mathrm{rub}^{0}$ 'The man "tobaccoes" the dog (to ward off fleas).'

A subset of intransitive motion verbs can become transitive by adding an object marker followed by the thematic consonant $k^{5}$ 'with'. No other stems generate this type of comitative applicative.

(30) Simple intransitive (a) and comitative applicative (b) motion verb form

a.

$$
\begin{array}{ll}
d e^{\prime} \eta & d^{8}-i k^{7}-i n^{2}-\text { bes }^{0}-n^{-1} \\
\text { people } & 3 \mathrm{SBJ}^{8} \text {-into.open.space }{ }^{7} \text {-PAST }{ }^{2} \text {-pass }{ }^{0} \text {-ANIM.PL.SBJ }
\end{array}
$$

'The people arrived.'

b. $\quad d e^{\prime} \eta \quad d^{8}-i k^{7}-b o^{6}-k^{5}-i n^{2}-b e s^{0}-n^{-1}$

people $3 \mathrm{SBJ}^{8}$-into.open.space ${ }^{7}$-1SG.OBJ ${ }^{6}$-with ${ }^{5}$-PAST ${ }^{2}$-pass ${ }^{0}$-ANIM.PL.SBJ ${ }^{-1}$

'The people brought me.' 'The people arrived with me.'

Aspect-related categories play a significant role in verb morphology. Single vs. multiple action is distinguished in many stems. Inceptivity is another prominent lexical category. Finally, the distinction between action vs. resultant state is also regularly marked by the stem morphology. The examples in (31) show several highly productive stem creation models used to express contrasts in lexical aspect:

(31) Lexically related verbs containing the action nominal toqojiy 'dry off'

a. $\quad d a^{8}=$ toqojig $7 \eta^{7}-q^{5}-i^{4}-b^{3}-t^{0}$

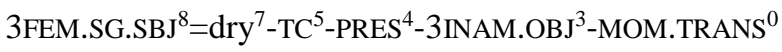

'She begins drying it off (once).' 'She dries it off (once)'

b. $\quad d a^{8}=$ toqojig $\eta^{7}-q^{5}-s^{4}-a^{1}-t n^{0}$

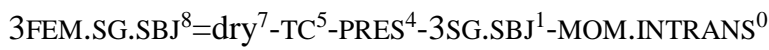

'She begins drying off (once).' 'She dries off (once).' 
c. $\quad d a^{8}=$ toqojin $^{7}-q^{5}-s^{4}-q u t^{0}$

3FEM.SG.SBJ ${ }^{8}=\mathrm{dry}^{7}-\mathrm{TC}^{5}$-PRES ${ }^{4}$-SG.SBJ.RESULT ${ }^{0}$

'She is dried off (stative-resultative form).'

d. $\quad d^{8}=$ toqojin $^{7}-q^{5}-s^{4}-$ dam $^{0}-i n^{-1}$

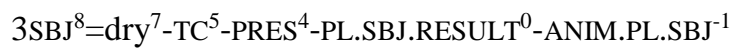

'They (animate-class) are dried off (stative-resultative form).'

e. $\quad d a^{8}=$ toqojiin ${ }^{7}-q^{5}-a^{4}-b^{3}-d a^{0}$

3FEM.SG.SBJ ${ }^{8}=$ dry $^{7}-$ TC $^{5}$-PRES ${ }^{4}-3$ INAM.OBJ $^{3}$-ITER.TRANS ${ }^{0}$

'She dries it off (many times).'

e. $\quad d a^{8}=$ toqojig ${ }^{7}-q^{5}-s^{4}-a^{1}-d i j^{0}$

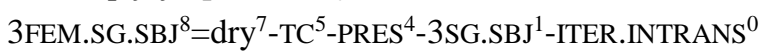

'She dries off (many times).'

These patterns were originally inceptives based on the root $* d a q$ 'put' and thematic $q^{5}$ 'inside' that literally meant ' $\mathrm{S}$ puts $\mathrm{O}$ into the action of drying', ' $\mathrm{S}$ is put into the action of drying', etc. When action nominals were inserted into Ket stems to generate root-initial forms, the P0 base *daq 'put' became semantically secondary. It also merged phonologically with the circum-root intransitive/resultative prefix $*$ joand suffix $*_{-} e j \sim *_{-} \eta$ to form the aspect-related bases $t \sim t n \sim q u t \sim d a m^{5} \sim d a \sim d i j$ seen in (31a-e). Thematic $q^{5}$ in these stems also grammaticalized into a opaque stem element: 'inside' $\rightarrow$ 'inceptive' $\rightarrow$ 'thematic consonant', as the patterns in question evolved into highly productive means of distinguishing single vs. repeated action and action vs. resultant state. Today, the inceptive meaning remains functional only in certain single-action stems.

The Ket verbal lexicon is atomistic in that stems are formally connected with other stems primarily through the template's position class structure. There is no

\footnotetext{
${ }^{5}$ The base $-d a m^{0}+$ animate-class plural agreement suffix $-i n^{-1}$ has merged to - damin $^{0}$ in forms with inanimate-class plural subjects, apparently through reanalysis of $-i n^{-1}$ as part of the plural base $-d a m^{0}$ in contrast with the singular base $-q u t^{0}$ :

(a) inanimate-class plural resultative form

$$
\begin{aligned}
& \text { toqojin }^{7}-q^{5}-i^{4}-b^{3} \text {-damin } \\
& \text { dry }^{7}-\text { TC }^{5}-\text { PRES }^{4} \text {-3INAN.SBJ }
\end{aligned}
$$

'They (inanimate-class) are dried off.'

(b) inanimate-class singular resultative form toqojig ${ }^{7}-q^{5}-i^{4}-b^{3}-q u t^{0}$

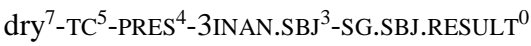
'It is dried off.'

Outside this pattern, no other verbs with inanimate-class plural subjects contain the suffixal element -in.
} 
straightforward affixal derivation of the type commonly found in the more familiar families of Eurasia. Instead, we might speak of 'formulaic derivation', where certain stem formulas, such as those illustrated in (31), share a predictable, schematized relationship.

\section{Conclusion}

The discussion has shown that nearly every typological generalization about the Ket verb must be qualified in some way. Alignment is nominative-accusative, but animacy, volition and activeness also play a role in agreement, as would be more typical of a language with active alignment. The verb's formal structure can be interpreted in typologically contradictory ways, as well. The original Yeniseian verb was strongly prefixing, yet Modern Ket has partly adapted the prefixing template into a suffixing arrangement under areal pressure. Under the same pressure, the position P8 subject prefixes have become special clitics in most verb forms but not in all. What has remained steadfast is the position class technique of verb formation itself. The straightjacket of the template even seems to have dictated what changed and how it changed. Metathesis and reanalysis, which are marginal factors in regular affixal morphology, have figured as leading techniques of innovation in Ket templatic verb morphology. The resulting dissonance of form and function in the Ket verb is thus an artifact of areal pressure combined with the conservatism of the inherited template.

Defining a Ket verb stem and listing it in a dictionary poses logistic challenges not encountered with most other Eurasian languages. Verbs in Indo-European, Uralic, Turkic, Mongolic, and Turkic languages are easily treated lexicographically as a word-like stem followed by a slot (or grid of slots) for grammatical endings. This familiar structure can be conveniently alphabetized in a dictionary using a citation form like the infinitive followed by information about conjugation class and any irregular morphological changes, or by listing the bare stem itself, which resembles a pared-down word-form equally amenable to alphabetical ordering. Ket finite verbs, by contrast, must be listed as positional formulas that specify disjunct lexical morphemes, the location of subject and object agreement markers, and the form of tense-mood affixes. Omitting any of this information from the lexical entry of a Ket verb renders the description incomplete and ultimately unusable. 
Abbreviations

$\begin{array}{ll}\text { ANIM } & \text { animate-class } \\ \text { DETRANS } & \text { detransitive } \\ \text { FEM } & \text { feminine-class } \\ \text { IMP } & \text { imperative } \\ \text { IMPERF } & \text { imperfective aspect } \\ \text { INTRANS } & \text { intransitive } \\ \text { MASC } & \text { masculine-class } \\ \text { MOM } & \text { single action } \\ \text { OBJ } & \text { object } \\ \text { PERF } & \text { perfective aspect } \\ \text { PL } & \text { plural } \\ \text { PRES } & \text { present tense } \\ \text { RESULT } & \text { resultative } \\ \text { SBJ } & \text { subject } \\ \text { SG } & \text { singular } \\ \text { TC } & \text { thematic consonant } \\ \text { TRANS } & \text { transitive }\end{array}$

\section{References}

Belimov, Eduard. 1991. Ketskij sintaksis: situatsija, propozitsija, predlozhenie. Novosibirsk: Nauka.

Butorin, Sergej. 1995. Opisanie morfologicheskoj struktury finitnoj glagol'noj slovoformy ketskogo jazyka s ispol'zovaniem metodiki porjadkovogo chlenenija. Unpublished Candidate Degree Dissertation. Novosibirsk.

Dul'zon, Andrej. 1968. Ketskij jazyk. Tomsk: Tomsk State University.

Kotorova, Elizaveta and Nefedov, Andrej (eds). 2015. Comprehensive dictionary of Ket with Russian, German and English translations. Munich: Lincom Europa.

Krejnovich, E. A. 1968. Glagol ketskogo jazyka. Leningrad: Nauka.

Nefedov, Andrey; Malchukov Andrej and Vajda, Edward. 2010. Ditransitive constructions in Ket. In: Malchukov, Andrej; Haspelmath, Martin and Comrie, Bernard (eds.) Studies in ditransitive constructions: a comparative handbook. Berlin and New York: Mouton de Gruyter. 352-381.

Nefedov, Andrey; Malchukov, Andrej and Vajda, Edward. 2011. Impersonal constructions in Ket. In: Malchukov, Andrej and Siewierska, Anna (eds.) 
Impersonal constructions: a cross-linguistic perspective. Amsterdam and New York: John Benjamins. 439-458.

Reshetnikov, Kirill and Starostin, Georgij. 1995. Struktura ketskoj glagol'noj slovoformy. In: Starostin, Sergej (ed.) Ketskij sbornik 4. Moskva: Vostochnaja Literatura. 7-121.

Vajda, Edward. 2001. The role of position class in Ket verb morphophonology. Word 52/3. 369-436.

Vajda, Edward. 2003. Ket verb structure in typological perspective. Sprachtypologie und Universalienforschung 56: 1/2. 55-92. Berlin: Akademie Verlag.

Vajda, Edward. 2004. Ket. Munich: Lincom. (Languages of the World/Materials 204)

Vajda, Edward. 2009. Loanwords in Ket. In: Haspelmath, Martin and Tadmor, Uri (eds.) Loanwords in the World's languages: a comparative handbook. Berlin: Mouton de Gruyter. 471-494.

Vajda, Edward. 2013. Metathesis and reanalysis in Ket. Tomsk journal of linguistics and anthropology 1/1. 14-26.

Vajda, Edward. 2015. Valency properties of the Ket verb clause. In: Malchukov, Andrej and Comrie, Bernard (eds.) Valency classes in the world's languages. Berlin and New York: Mouton de Gruyter. 630-668.

Vajda, Edward. (in press 1). Ket incorporation. In: Fortescue, Michael; Mithun, Marianne and Evans, Nicholas (eds.) Handbook of Polysynthesis. Oxford: Oxford University Press.

Vajda, Edward. (in press 2). Patterns of innovation and retention in templatic polysynthesis. Fortescue, Michael; Mithun, Marianne and Evans, Nicholas (eds.) Handbook of Polysynthesis. Oxford: Oxford University Press.

Vajda, Edward \& Heinrich Werner. (in preparation). Etymological dictionary of the Yeniseian Languages.

Werner, Heinrich. 1997. Die ketische Sprache. Wiesbaden: Harrassowitz. 